\title{
Chemical composition and antioxidant capacities of phytococktail extracts from trans-Himalayan cold desert
}

\author{
Priyanka Dhar ${ }^{1}$, Prabodh Kumar Bajpai ${ }^{1}$, Amol Bapurao Tayade ${ }^{1}$, Om Prakash Chaurasia ${ }^{\text {** }}$,
} Ravi Bihari Srivastava ${ }^{1}$ and Shashi Bala Singh ${ }^{2}$

\begin{abstract}
Background: Himalayan plants are widely used in traditional system of medicine both as prophylactics and therapeutics for high altitude maladies. Our aim was to evaluate the antioxidant capacities and bioactive compounds of methanol and $\mathrm{n}$-hexane extracts of the phytococktail comprising of sea buckthorn (Hippophae rhamnoides), apricot (Prunus armeniaca) and roseroot (Rhodiola imbricata) from trans-Himalaya.

Methods: The 1,1-diphenyl-2-picrylhydrazyl (DPPH), 2,2'-azinobis-(3-ethylbenzothiazoline-6-sulfonic acid) diammonium salt (ABTS) and nitric oxide (NO) radical scavenging capacities and lipid peroxidation inhibition (LPI) property of the extracts were determined. Total antioxidant power was determined by ferric reducing/antioxidant power (FRAP) assay. Total polyphenol, flavonoid, flavonol, proanthocyanidin and carotenoid were also estimated for both extracts. We have identified and quantified the phyto-chemotypes present in the methanol and $\mathrm{n}$-hexane extracts by hyphenated gas chromatography/mass spectrometry (GC/MS) technique.
\end{abstract}

Results: Antioxidant capacity assays using DPPH, ABTS, NO, LPI and FRAP exhibited analogous results where the phytococktail showed high antioxidant action. The phytococktail was also found to possess high quantity of total polyphenol, flavonoid, flavonol and carotenoid. A significant and linear correlation was found between the antioxidant capacities and bioactive principles. A total of 32 phyto-chemotypes were identified from these extracts by GC/MS chemometric fingerprinting. Major phyto-chemotypes identified by GC/MS were glycosides, phenylpropanoids and derivatives, terpenoids, alkaloids, phytosterols, fatty acids and esters, alkaloids and derivatives, organic acid esters and aromatic ethers with positive biological and pharmacological actions.

Conclusion: The phytococktail extracts were found to contain considerable amount of diverse bioactive compounds with high antioxidant capacities. The presence of hydrophilic and lipophilic antioxidants in the phytococktail could have contributed to the higher antioxidant values. Hence, the phytococktail could be used as natural source of antioxidants to ameliorate disorders associated with oxidative stress.

Keywords: Phytococktail, Sea buckthorn, Apricot, Roseroot, Antioxidant capacity, Total polyphenol content, GC/MS analysis

\footnotetext{
* Correspondence: dropchaurasiadihardrdo@gmail.com

'Defence Institute of High Altitude Research, Defence Research \&

Development Organisation, C/o 56 APO, Leh-Ladakh, Jammu \& Kashmir,

Pin 901205, India

Full list of author information is available at the end of the article
} 


\section{Background}

In oxidative stress condition, reactive oxygen species (ROS) are produced which play a vital role in the pathogenesis of several chronic diseases [1]. Extensive epidemiological studies have been conducted to ensure that intake of botanical products is linked with a reduced risk of several chronic diseases [2] and these positive properties of the plant products have been partly ascribed to the components that possess antioxidant capacities [3-6]. The natural antioxidants obtained from botanical resources have turned out to be an interesting alternative to synthetic antioxidants due to safety concerns and limitation of usage. Bioactive compounds from plants, for example, polyphenols, phenolic acids, flavonoids, flavonols, diterpenes, tannins, phytosterols, fatty acid esters, phenylpropanoids, alkaloids, glycosides etc. have received great interest in medicinal chemistry and natural product research for their high antioxidant properties [7]. Isolation and structural elucidation of these bioactive compounds is of prime importance in natural product research to identify and evaluate the therapeutic potential of medicinal plants. Numerous extraction techniques and analytical systems have been developed for the analysis and characterization of active compounds from medicinal plants. Gas chromatography/mass spectrometry (GC/MS) has become an ideal technique for qualitative and quantitative analysis of volatile and semivolatile compounds of plant origin [8].

The high altitude region of trans-Himalayan cold desert possesses adverse climatic conditions for human survival. Sustained energy deficit, malnutrition, vitamin and mineral deficiency and metabolic disorders could occur in this unfavorable environment due to alteration in physiological function [9-11]. However, the Himalaya also has the deep underlying remedy to combat these problems in its diverse flora and fauna. Plants of high altitude Himalaya are widely used in traditional system of medicine both as prophylactics and therapeutics for high altitude maladies. In recent times, a number of herbal products have been formulated from our institute using the native plants of this region [12]. We aimed at the preparation of a phytococktail comprising of sea buckthorn (Hippophae rhamnoides L., Elaeagnaceae), apricot (Prunus armeniaca L., Rosaceae) and roseroot (Rhodiola imbricata Edgew., Crassulaceae) which may be capable of providing additional physiological benefits and basic nutritional requirements in these extreme climatic conditions. The selected plants are widely used in the traditional system of medicine for treatment of common ailments. The advancement in the health promoting properties has led to use them as nutritional supplements [13-16]. The bioactive phytochemical components, medicinal values, therapeutic potential and nutritional properties of these three plants have been extensively studied by previous researchers [6,17-20] and the plant parts having medicinal properties were also reported to be safe and non-toxic [21-26]. We studied the methanol (hydrophilic) and n-hexane (lypophilic) extracts of the phytococktail to measure the total antioxidant capacity because both hydrophilic and lypophilic antioxidants contribute to the total antioxidant capacity. Additionally, the relationship between bioactive compounds and antioxidant capacities of hydrophilic and lipophilic extracts of the phytococktail is still unknown. Therefore, the objective of the present study was to evaluate the antioxidant capacities of the phytococktail extracts by different assays, including DPPH, ABTS, NO, LPI and FRAP methods and their correlation with bioactive compounds present in the extracts. In addition, we performed hyphenated GC/MS analysis to identify and quantify the phyto-chemotypes present in the methanol and $n$-hexane extracts of the phytococktail.

\section{Methods}

\section{Chemicals}

1,1-diphenyl-2-picrylhydrazyl radical (DPPH'), 2,2'-azinobis(3-ethylbenzothiazoline-6-sulfonic acid) diammonium salt (ABTS), 2,4,6-tripyridyl-s-triazine (TPTZ), ferrous sulfate $\left(\mathrm{FeSO}_{4} .7 \mathrm{H}_{2} \mathrm{O}\right)$, aluminium chloride $\left(\mathrm{AlCl}_{3}\right)$, sodium acetate $\left(\mathrm{C}_{2} \mathrm{H}_{3} \mathrm{NaO}_{2}\right)$, sodium carbonate $\left(\mathrm{Na}_{2} \mathrm{CO}_{3}\right)$, potassium persulfate $\left(\mathrm{K}_{2} \mathrm{~S}_{2} \mathrm{O}_{8}\right)$, potassium chloride $(\mathrm{KCl})$, ferric chloride $\left(\mathrm{FeCl}_{3} \cdot 6 \mathrm{H}_{2} \mathrm{O}\right)$, sodium nitroprusside $\left(\mathrm{Na}_{2}\left[\mathrm{Fe}(\mathrm{CN})_{5} \mathrm{NO}\right]\right.$. $\left.2 \mathrm{H}_{2} \mathrm{O}\right)$, egg yolk emulsion, sulfanilic acid $\left(\mathrm{C}_{6} \mathrm{H}_{7} \mathrm{NO}_{3} \mathrm{~S}\right)$, naphthyethylenediamine dihydrochloride, glacial acetic acid, butylated hydroxytoluene (BHT), butylated hydroxyanisole (BHA), ascorbic acid, quercetin and catechin were purchased from Sigma-Aldrich (St. Louis, MO, USA). FolinCiocalteu's phenol reagent, vanillin, hydrochloric acid, sulphuric acid, methanol, n-hexane, chloroform, ethanol and sodium carbonate were purchased from Merck Chemical Supplies (Merck KGaA, Darmstadt, Germany). All other chemicals used including solvents were of analytical grade.

\section{Plant materials}

The flora of trans-Himalayan Ladakh region was extensively studied by previous investigators $[27,28]$. Based on the medicinal, nutritional and therapeutic potential, three native plants of this region viz. sea buckthorn (Hipppophae rhamnoides L. subspecies turkestanica, family Elaeagnaceae), apricot (Prunus armeniaca L., family Rosaceae) and roseroot (Rhodiola imbricata, family Crassulaceae) were selected to develop the phytococktail.

Sea buckthorn (H. rhamnoides) berries were collected from Choglamsar village of Leh, Ladakh, India [altitude $3500 \mathrm{~m}$ above mean sea level (MSL), latitude $34^{\circ}$ 6'38.9664" N, longitude $77^{\circ} 35^{\prime} 10.3992 " \mathrm{E}$ ], in September, 2010. The fruits of $P$. armeniaca (apricot, halman variety) were collected from apricot field gene bank of Defence 
Institute of High Altitude Research, Leh (altitude 3500 m above MSL, latitude $34^{\circ} 8^{\prime} 16.119^{\prime \prime} \mathrm{N}$, longitude $77^{\circ} 34^{\prime} 19.2216^{\prime \prime}$ E), in September, 2010. Roots of $R$. imbricata (roseroot), were collected from the Changthang valley of transHimalayan region (Chang-La Top, altitude $5330 \mathrm{~m}$ above MSL, latitude $34^{\circ} 2^{\prime} 49.812^{\prime \prime} \mathrm{N}$, longitude $77^{\circ} 55^{\prime} 49.7778^{\prime \prime} \mathrm{E}$ ) of India in the month of October, 2010 after the period of senescence. All necessary permits were obtained from the concerned authorities for collection of plant materials. Collected plant specimens were carefully examined and identified by Dr. Om Prakash Chaurasia, renowned plant taxonomist and principal scientist of Medicinal and Aromatic Plant (MAP) Division of our institute. The voucher specimens of $H$. rhamnoides (HR 6-8), P. armeniaca (PR 4-6) and R. imbricata (RI 5-7) have been deposited at the institutional herbarium for future reference.

\section{Processing of plant materials and preparation of phytococktail}

Mechanical pulping of sea buckthorn berries and apricot fruits yielded raw pulp that were $50 \%$ and $70 \%$ of the fruit weight. The pulp was then lyophilized using a Lyophilizer (Model ALPHA 2-4 LDplus, Martin Christ Gefriertrocknungsanlagen $\mathrm{GmbH}$, Osterode am Harz, Germany) to obtain the dry pulp powder and stored in airtight food grade container at $-80^{\circ} \mathrm{C}$, till the formulation of the phytococktail. Roots of $R$. imbricata were washed thoroughly, cut into small pieces and shade dried at room temperature for 15 days. Root dry matter content (DMC) was calculated as the percentage of dry weight relative to fresh weight [DMC (\%) = Sample dry weight $\times 100$ / Sample fresh weight]. The DMC was 28$33 \%$. Then they were finely powdered and used for extraction. The root powder was taken for extraction in $80 \%$ ethanol by Soxhlet apparatus (Borosil GlassWorks Limited, Worli, Mumbai, India). The ethanolic fraction was concentrated by rotary evaporator (Rotavapor ${ }^{\circledR}-210$, Büchi Labortechnik AG, Flawil, Switzerland) under reduced pressure at $40^{\circ} \mathrm{C}$ by circulation of cold water using thermostat maintained at $4^{\circ} \mathrm{C}$ in order to minimize the degradation of thermolabile compounds and lyophilized to obtain dry extract.

The powdered materials of $H$. rhamnoides fruit pulp, $P$. armeniaca fruit pulp and $R$. imbricata dry root extract were taken in the ratio of 100:50:1 $(\mathrm{mg} / \mathrm{ml})$ [29-31], mixed properly and dissolved in water to get a homogenous mixture of the phytococktail. It was then lyophilized to obtain the dry cocktail. To avoid contamination, clean and sterile conditions were maintained during the whole process.

\section{Preparation of the phytococktail extract}

Soxhlet extraction was carried out with 10 gm of ground dried phytococktail with methanol and n-hexane at $40^{\circ} \mathrm{C}$.
The mixture was subsequently filtered (Whatman No. 5) on a Büchner funnel, the filtrate was then evaporated to dryness under reduced pressure at $40^{\circ} \mathrm{C}$ and lyophilized to obtain the dry extracts. Yield of the extracts were $30 \%$ (methanol extract) and 10\% (n-hexane extract) of the dry phytococktail.

\section{DPPH radical scavenging assay}

The effect of extract on DPPH radical was determined using a previously described method [32]. A solution of $0.135 \mathrm{mM}$ DPPH in methanol was prepared and $100 \mu \mathrm{l}$ of this solution was mixed with $100 \mu \mathrm{l}$ of the phytococktail extract. The concentration of plant extracts was 20-500 $\mu \mathrm{g} / \mathrm{ml}$. The reaction mixture was vortexed thoroughly and left in the dark at room temperature for $30 \mathrm{~min}$. The absorbance of the mixture was measured spectrophotometrically at $517 \mathrm{~nm}$. Quercetin (QR), ascorbic acid (AA) and butylated hydroxytoluene (BHT) were used as standards. The ability to scavenge DPPH radical was calculated by the following equation: $\mathrm{DPPH}$ radical scavenging capacity $\left.(\%)=\left[\left(\mathrm{Abs}_{\text {control }}-\mathrm{Abs}_{\text {sample }}\right)\right] /\left(\mathrm{Abs}_{\text {control }}\right)\right] \times 100$, where, $\mathrm{Abs}_{\text {control }}$ is the absorbance of DPPH radical + methanol; $\mathrm{Abs}_{\text {sample }}$ is the absorbance of DPPH radical with sample extract or standard.

The half maximal inhibitory concentration $\left(\mathrm{IC}_{50}\right)$ for scavengers (radical scavenging concentration 50 or $\mathrm{RS}_{50}$ ), the amount of antioxidant required to decrease the initial DPPH concentration by $50 \%$, termed as efficiency concentration $\left(\mathrm{EC}_{50}\right)$ and the effectiveness of antioxidant and radical scavenging capacity demonstrated as antiradical power (ARP) were calculated [33-36]. The $\mathrm{RSa}_{50}$ value was determined by plotting the scavenging capacity against the logarithm of sample concentration. The $\mathrm{EC}_{50}$ was calculated from the following formula:

$$
\mathrm{EC}_{50}=\mathrm{IC}_{50} /[\mathrm{DPPH}] \text { in } \mathrm{mg} / \mathrm{ml}
$$

The ARP was also determined as follows:

$$
\mathrm{ARP}=1 /\left(\mathrm{EC}_{50} \times 100\right)
$$

The results were expressed as ascorbic acid equivalent antioxidant capacity (AEAC) [37] using the following equation:

$$
\mathrm{AEAC}=\left(\mathrm{IC}_{50(\mathrm{AA})} / \mathrm{IC}_{50(\text { sample })}\right) \times 10^{5}
$$

\section{ABTS radical scavenging assay}

The ABTS assay was performed as described by previous investigators [38]. The stock solutions included $7 \mathrm{mM}$ ABTS solution and 2.4 $\mathrm{mM}$ potassium persulfate (PPS) solution. The working solution was then prepared by mixing the two stock solutions in equal quantities and allowing them to react for $12 \mathrm{~h}$ at room temperature in 
dark. The solution was then diluted by mixing $1 \mathrm{ml}$ $\mathrm{ABTS}^{++}$solution with $60 \mathrm{ml}$ of methanol to obtain an absorbance of $0.706 \pm 0.001$ units at $734 \mathrm{~nm}$ using spectrophotometer (Spectramax $\mathrm{M}_{2}{ }^{\mathrm{e}}$, Molecular Devices, Germany). The concentration of plant extracts was 20$500 \mu \mathrm{g} / \mathrm{ml}$. Plant extracts $(100 \mu \mathrm{l})$ were allowed to react with $100 \mu \mathrm{l}$ of the $\mathrm{ABTS}^{+}$solution and the absorbance was taken at $734 \mathrm{~nm}$ after $7 \mathrm{~min}$ incubation at $25^{\circ} \mathrm{C}$ in 96 well plate. The $\mathrm{ABTS}^{+}$scavenging capacity of the extracts was compared with that of QR, AA and BHT. The scavenging percentage was calculated as follows:

ABTS radical scavenging capacity $(\%)=\left[\left(\mathrm{Abs}_{\text {control }}-\right.\right.$ $\left.\left.\left.\mathrm{Abs}_{\text {sample }}\right)\right] /\left(\mathrm{Abs}_{\text {control }}\right)\right] \times 100$,

where, $\mathrm{Abs}_{\text {control }}$ is the absorbance of ABTS radical + methanol; $\mathrm{Abs}_{\text {sample }}$ is the absorbance of ABTS radical with sample extract or standard.

The $\mathrm{RSa}_{50}, \mathrm{EC}_{50}$, ARP and AEAC values were also calculated as described in the previous section.

\section{Inhibition of lipid peroxidation}

A modified thiobarbituric acid reactive species (TBARS) assay was used to measure the lipid peroxide formed using egg yolk homogenates as lipid-rich media [39]. Briefly, readymade egg yolk emulsion was diluted to $10 \%$ v/v with $1.15 \% \mathrm{w} / \mathrm{v} \mathrm{KCl}$ and mixed thoroughly. The reaction solution $(400 \mu \mathrm{l})$ consisted of $50 \mu \mathrm{l}$ egg yolk emulsion, $50 \mu \mathrm{l}$ of sample solution in different concentrations (2.5-500 $\mu \mathrm{g} / \mathrm{ml}$ ), $150 \mu \mathrm{l}$ of $20 \%$ (aqueous) trichloroacetic acid and $150 \mu \mathrm{l}$ of $0.67 \% \mathrm{w} / \mathrm{v}$ thiobarbituric acid. The whole reaction solution was then vortexed thoroughly and followed by incubation at $95^{\circ} \mathrm{C}$ for $1 \mathrm{~h}$. After cooling, equal volume of butanol was added (in case of $\mathrm{n}$-hexane extract) and the mixture was centrifuged at $3000 \mathrm{rpm}$ for $10 \mathrm{~min}$. Absorbance of the upper layer was measured at $532 \mathrm{~nm}$ and percentage inhibition was calculated with the following formula:

$\%$ inhibition of lipid peroxidation $=(1-\mathrm{t} / \mathrm{c}) \times 100$, where $\mathrm{c}$ is the absorbance of fully peroxidized control and $t$ is the absorbance of test sample. $\alpha$-tocopherol, BHA and BHT were used as reference standards. The $\mathrm{IC}_{50}$ value was calculated from the regression equation between sample concentration and rate of inhibition.

\section{Nitric oxide radical scavenging assay}

The nitric oxide radical scavenging capacity of the phytococktail extracts was determined by previously established method [40]. The reaction solution $(300 \mu \mathrm{l})$ containing $250 \mu \mathrm{l}$ of $10 \mathrm{mM}$ sodium nitroprusside in PBS (pH 7.0) was mixed with $50 \mu$ l phytococktail extracts at different concentrations $(20-500 \mu \mathrm{g} / \mathrm{ml})$ and followed by incubation at $37^{\circ} \mathrm{C}$ for $1 \mathrm{~h}$. After that, $125 \mu \mathrm{l}$ aliquot was mixed with $125 \mu \mathrm{l}$ Griess reagent [1 $\mathrm{ml}$ of sulfanilic acid reagent $(0.33 \%$ prepared in $20 \%$ glacial acetic acid at room temperature for $5 \mathrm{~min}$ ) mixed with
$1 \mathrm{ml}$ of naphthyethylenediamine dihydrochloride $(0.1 \% \mathrm{w} / \mathrm{v})]$ and the absorbance was measured at $540 \mathrm{~nm}$. BHA was used as the positive standard. The scavenging percentage of nitric oxide generated was measured by comparing with the absorbance value of negative control (10 mM sodium nitroprusside and PBS) by the formula described earlier.

\section{Total antioxidant capacity (FRAP assay)}

FRAP assay was carried out to determine the total antioxidant capacity of the phytococktail extracts [41]. The stock solutions included $300 \mathrm{mM}$ acetate buffer (3.1 g $\mathrm{CH}_{3} \mathrm{COONa}$ and $\left.16 \mathrm{ml} \mathrm{CH}_{3} \mathrm{COOH}\right), \mathrm{pH} 3.6,10 \mathrm{mM}$ TPTZ (2, 4, 6-tripyridyl-s-triazine) solution in $40 \mathrm{mM}$ $\mathrm{HCl}$ and $20 \mathrm{mM} \mathrm{FeCl}_{3} \cdot 6 \mathrm{H}_{2} \mathrm{O}$ solution. The fresh working solution was prepared by mixing $25 \mathrm{ml}$ acetate buffer, $2.5 \mathrm{ml} \mathrm{TPTZ}$ and $2.5 \mathrm{ml} \mathrm{FeCl} 3 \cdot 6 \mathrm{H}_{2} \mathrm{O}$. Plant extracts $(15 \mu \mathrm{l})$ were allowed to react with $285 \mu \mathrm{l}$ of the FRAP solution for $30 \mathrm{~min}$ in dark. Observations of the colored product (ferrous tripyridyltriazine complex) were taken at $593 \mathrm{~nm}$. The calibration curve was prepared from the equation $y=0.097 x-0.048, R^{2}=0.993$, where $x$ was $a b-$ sorbance and y was $\mathrm{FeSO}_{4}$ concentration (mol). Linearity was achieved between $1 \times 10^{-4}$ and $1 \times 10^{-3} \mathrm{~mol} \mathrm{FeSO}_{4}$. Results were expressed in mol Fe (II)/g of extract and compared with that of QR, AA and BHT.

\section{Total polyphenol assay}

Total polyphenol content was measured using FolinCiocalteu colorimetric method as described by previous investigators [42]. The phytococktail methanol and n-hexane extracts $(10 \mu \mathrm{l})$ was mixed with $20 \mu \mathrm{l}$ of Folin-Ciocalteu reagent and $200 \mu \mathrm{l}$ of $\mathrm{H}_{2} \mathrm{O}$, and incubated at room temperature for $3 \mathrm{~min}$. Following the addition of $100 \mu \mathrm{l}$ of $20 \%$ sodium carbonate to the mixture, total polyphenol was determined after $1 \mathrm{~h}$ of incubation at room temperature. The absorbance of the resulting blue color was measured at $765 \mathrm{~nm}$. Quantification was done with respect to the standard curve of gallic acid. The polyphenol content was expressed as gallic acid equivalent (GAE) using the following equation based on the calibration curve: $y=$ $0.005 x+0.059, R^{2}=0.987$, where $x$ was absorbance and $y$ was GAE (mol/g of extract) at a final concentration of $100 \mu \mathrm{g} / \mathrm{ml}$.

\section{Total flavonoid assay}

Estimation of total flavonoid in the methanol and nhexane extracts was carried out using the previous method [43]. Briefly, to $100 \mu \mathrm{l}$ of sample, $100 \mu \mathrm{l}$ of $2 \%$ $\mathrm{AlCl}_{3}$ ethanol solution was added. The contents were incubated for $1 \mathrm{~h}$ at room temperature and the absorbance was measured at $420 \mathrm{~nm}$. Total flavonoid content was calculated as quercetin equivalent $(\mathrm{QE})$ using the following equation based on the calibration curve: $y=0.011 x+$ 
$0.038, \mathrm{R}^{2}=0.984$, where $\mathrm{x}$ was absorbance and $\mathrm{y}$ was $\mathrm{QE}$ (mol/g of extract) at a final concentration of $100 \mu \mathrm{g} / \mathrm{ml}$.

\section{Total flavonol assay}

Total flavonol in the extracts was also estimated by the method described previously [44]. To $100 \mu$ l extract, 100 $\mu \mathrm{l}$ of $2 \% \mathrm{AlCl}_{3}$ ethanol and $150 \mu \mathrm{l}(50 \mathrm{~g} / \mathrm{l})$ sodium acetate solutions were added. The absorbance at $440 \mathrm{~nm}$ was measured after $2.5 \mathrm{~h}$ at $20^{\circ} \mathrm{C}$. Total flavonol content was calculated as quercetin equivalent (QE) using the following equation based on the calibration curve: $y=0.016 x+0.001, R^{2}=0.985$, where $x$ was absorbance and $y$ was $\mathrm{QE}$ (mol/g of extract) at a final concentration of $100 \mu \mathrm{g} / \mathrm{ml}$.

\section{Total proanthocyanidin assay}

Total proanthocyanidin test was performed by vanillin$\mathrm{HCl}$ assay with minor modification [45]. Vanillin reagent (1\%) was prepared in methanol and incubated at $30^{\circ} \mathrm{C}$ before use. The working reagent was prepared by mixing one part of $1 \%$ vanillin solution and one part of $8 \% \mathrm{HCl}$ solution in methanol. The reaction mixture contained working vanillin reagent $(100 \mu \mathrm{l})$ and plant extracts $(20 \mu \mathrm{l})$. The absorbance at $500 \mathrm{~nm}$ was measured after $20 \mathrm{~min}$ at $30^{\circ} \mathrm{C}$. Total proanthocynidin content was calculated as catechin equivalent (CE) using the following equation based on the calibration curve: $y=0.327 x+$ $0.039, R^{2}=0.973$, where $x$ was absorbance and $y$ was $C E$ (mol/g of extract) at a final concentration of $100 \mu \mathrm{g} / \mathrm{ml}$.

\section{Determination of total carotenoids}

The phytococktail extracts of the appropriate concentration $(1 \mathrm{mg} / \mathrm{ml})$ were analyzed in spectrophotometer at 470, 653 and $666 \mathrm{~nm}$. The concentration of total carotenoid was determined [46]. The carotenoid concentration was expressed in $\mathrm{mg} / \mathrm{g}$ of extract.

\section{GC/MS analysis}

\section{Preparation of sample for GC/MS analysis}

The $100 \mathrm{mg}$ and $50 \mathrm{mg}$ concentrated methanol and n-hexane extracts of phytococktail were dissolved in $25 \mathrm{ml}$ of respective solvents, vortexed properly and filtered through $0.22 \mu \mathrm{m}$ syringe filter (Millipore Corp., Bedford, MA, USA). One microlitre aliquot of the sample solution was then injected into the GC/MS MS system for the requisite analysis.

\section{Instrumentation and chromatographic conditions}

GC/MS analysis was carried out on a Thermo Finnigan PolarisQ Ion Trap GC/MS MS system comprising of an AS2000 liquid autosampler (Thermo Finnigan, Thermo Electron Corporation, Austin, TX, USA) and the peaks in the chromatogram were identified on the basis of their mass spectra as per our previous report [19]. The gas chromatograph was interfaced to a mass spectrometer instrument employing the following conditions viz. Durabond DB-5 ms column (30 $\mathrm{m} \times 0.25 \mathrm{~mm} \times$ $0.25 \mu \mathrm{m}$ ), operating in electron impact [electron ionisation positive $\left.\left(\mathrm{EI}^{+}\right)\right]$mode at $70 \mathrm{eV}$, helium $(99.999 \%)$ as carrier gas at a constant flow of $1 \mathrm{ml} / \mathrm{min}$ and an injection volume of 0.5 EI (split ratio of 10:1), injector temperature $280^{\circ} \mathrm{C}$ and transfer line temperature $300^{\circ} \mathrm{C}$. The oven temperature was programmed from $50^{\circ} \mathrm{C}$ (isothermal for $2 \mathrm{~min}$ ), with gradual increase in steps of $10^{\circ} \mathrm{C} / \mathrm{min}$, to $300^{\circ} \mathrm{C}$. Mass spectra were taken at $70 \mathrm{eV}$, a scan interval of $0.5 \mathrm{~s}$ and full mass scan range from $25 \mathrm{~m} / \mathrm{z}$ to $1000 \mathrm{~m} / \mathrm{z}$. The data acquisition was performed on Finnigan Xcalibur data acquisition and processing software version 2.0 (ThermoQuest, LC and LC/MS Division, San Jose, California, USA).

\section{Identification of components}

Interpretation of mass spectrum of GC/MS was done using the NIST/EPA/NIH Mass Spectral Database (NIST11), with NIST MS search program v.2.0 g [National Institute Standard and Technology (NIST), Scientific Instrument services, Inc., NJ, USA]. The mass spectrum of the unknown component was compared with the spectrum of the known components stored in the NIST library. The name, molecular weight and structure of the components of the test materials were ascertained.

\section{Statistical analysis}

All the experimental results are expressed as mean \pm standard deviation (SD) using statistical analysis with SPSS 17.0 (Statistical Program for Social Sciences, SPSS Corporation, Chicago, IL) version. Analysis of variance (ANOVA) in a completely randomized design, Duncan's multiple range test and Pearson's correlation coefficients were performed to compare the data. Post hoc analysis was performed using Neuman Keuls Test, and values with $p<0.05$ were considered significant.

\section{Results}

\section{DPPH radical scavenging capacity}

The free radical scavenging capacity of the phytococktail methanol and n-hexane extracts and the three positive controls viz. QR, AA and BHT were compared through their ability to scavenge DPPH radical. The $\mathrm{RSa}_{50}$ values were found to be 393.57, 319, 8.09, 9.23 and $51.92 \mu \mathrm{g} / \mathrm{ml}$ for methanol extract, n-hexane extract, QR, AA and BHT respectively. The DPPH scavenging capacity of the phytococktail extracts and the positive controls, expressed as $\mathrm{EC}_{50}$ value, were $7.39,5.99,0.15,0.17$ and $0.98 \mu \mathrm{g} / \mathrm{ml}$. The ARP values of methanol and $\mathrm{n}$-hexane extracts were also calculated and were found to be 13.53 and 16.69 respectively. AEAC values of the two extracts were correspondingly 2345.19 and 2893.41 (Table 1). 
Table 1 Effect of phytococktail methanol and $n$-hexane extracts on DPPH and ABTS radical-scavenging capacities ${ }^{a}$

\begin{tabular}{|c|c|c|c|c|c|c|c|c|c|c|}
\hline \multirow[t]{3}{*}{ Concentration $(\mu \mathrm{g} / \mathrm{ml})$} & \multirow[b]{3}{*}{$\mathrm{PCM}^{\mathrm{b}}$} & \multirow[b]{3}{*}{$\mathrm{PCH}^{\mathrm{c}}$} & \multicolumn{8}{|c|}{ Scavenging capacity (\%) } \\
\hline & & & \multicolumn{3}{|c|}{ DPPH radical-scavenging capacity } & \multicolumn{5}{|c|}{ ABTS radical-scavenging capacity } \\
\hline & & & $Q R^{d}$ & $A A^{\mathrm{e}}$ & $B H T^{f}$ & PCM & $\mathrm{PCH}$ & QR & $A A$ & BHT \\
\hline 2.5 & - & - & $19.92 \pm 1.53$ & $17.71 \pm 3.03$ & $6.64 \pm 0.78^{\# \Phi}$ & - & - & $35.24 \pm 3.43$ & $34.29 \pm 1.75$ & $7.43 \pm 1.33^{\# \Phi}$ \\
\hline 5 & - & - & $41.85 \pm 5.12$ & $32.23 \pm 8.30$ & $9.77 \pm 2.95^{\# \Phi}$ & - & - & $64.76 \pm 7.07$ & $66.14 \pm 15.94$ & $13.91 \pm 2.71^{\# \Phi}$ \\
\hline 10 & - & - & $63.22 \pm 4.50$ & $63.93 \pm 1.59$ & $15.30 \pm 1.13^{\# \Phi}$ & - & - & $86.84 \pm 1.57$ & $87.15 \pm 0.92$ & $27.71 \pm 1.10^{\# \Phi}$ \\
\hline 15 & - & - & $83.71 \pm 8.59$ & $77.93 \pm 4.40$ & $18.49 \pm 0.56^{\# \Phi}$ & - & - & $87.79 \pm 0.18$ & $87.69 \pm 0.18$ & $34.39 \pm 2.78^{\# \Phi}$ \\
\hline 20 & $3.45 \pm 2.26$ & $31.45 \pm 3.77^{*}$ & $87.83 \pm 0.24^{* \$}$ & $88.48 \pm 0.90^{*}$ & $25.33 \pm 0.81^{* \$ \# \Phi}$ & $3.29 \pm 0.49$ & $3.40 \pm 1.29$ & $87.79 \pm 0.18^{* \$}$ & $88.00 \pm 0.18^{* \$}$ & $42.36 \pm 0.55^{* \text {. } \# \Phi}$ \\
\hline 40 & $10.48 \pm 1.18$ & $34.05 \pm 3.10^{*}$ & $88.61 \pm 0.24^{* \xi}$ & $88.93 \pm 0.45^{*}$ & $36.78 \pm 5.88^{* \# \Phi}$ & $9.87 \pm 1.39$ & $4.25 \pm 0.66^{*}$ & $87.79 \pm 0.18^{* \$}$ & $87.90 \pm 0.00^{* \$}$ & 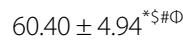 \\
\hline 60 & $13.61 \pm 0.30$ & $35.29 \pm 6.13^{*}$ & $88.93 \pm 0.09^{* \$}$ & $89.06 \pm 0.39^{*}$ & $58.07 \pm 4.29^{* \$ \# \Phi}$ & $15.29 \pm 3.23$ & $8.81 \pm 0.80^{*}$ & $88.11 \pm 0.18^{* \$}$ & $88.22 \pm 0.55^{* \$}$ & $74.84 \pm 1.39^{* \text { \$ } \# \Phi}$ \\
\hline 80 & $16.41 \pm 0.34$ & $41.15 \pm 3.28^{*}$ & $88.93 \pm 0.18^{* \$}$ & $89.26 \pm 0.39^{* \$}$ & $62.89 \pm 3.20^{* \$ \# \Phi}$ & $22.08 \pm 0.18$ & $22.93 \pm 2.87$ & $88.32 \pm 0.37^{* \$}$ & $88.22 \pm 0.55^{* \xi}$ & 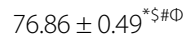 \\
\hline 100 & $20.38 \pm 2.79$ & $42.51 \pm 1.44^{*}$ & $89.13 \pm 0.24^{* \$}$ & $89.58 \pm 0.11^{* \$}$ & $65.30 \pm 3.07^{* \$ \# \Phi}$ & $30.15 \pm 1.51$ & $33.33 \pm 3.80$ & $88.43 \pm 0.49^{* \$}$ & $88.54 \pm 0.32^{* \xi}$ & 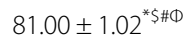 \\
\hline 150 & $27.99 \pm 1.59$ & $44.14 \pm 0.39^{*}$ & - & - & - & $44.27 \pm 1.39$ & $48.83 \pm 2.12^{*}$ & - & - & - \\
\hline 200 & $32.03 \pm 2.07$ & $44.66 \pm 0.63^{*}$ & - & - & - & $57.22 \pm 1.29$ & $61.36 \pm 2.41$ & - & - & - \\
\hline 250 & $34.18 \pm 1.56$ & $46.55 \pm 4.06^{*}$ & - & - & - & $64.65 \pm 1.65$ & $68.90 \pm 1.75^{*}$ & - & - & - \\
\hline 300 & $39.78 \pm 1.64$ & $49.35 \pm 0.49^{*}$ & - & - & - & $74.95 \pm 1.29$ & $73.57 \pm 2.23$ & - & - & - \\
\hline 400 & $49.35 \pm 2.47$ & $52.80 \pm 4.26$ & - & - & - & $85.46 \pm 0.80$ & $75.58 \pm 2.71^{*}$ & - & - & - \\
\hline 500 & $60.81 \pm 4.01$ & $59.05 \pm 5.21$ & - & - & - & $87.79 \pm 0.18$ & $76.43 \pm 3.91^{*}$ & - & - & - \\
\hline $\mathrm{RSa}_{50}$ values & 393.57 & 319.00 & 8.09 & 9.23 & 51.92 & 181.98 & 183.37 & 3.42 & 3.39 & 33.15 \\
\hline $\mathrm{EC}_{50}$ values & 7.39 & 5.99 & 0.15 & 0.17 & 0.98 & 2.84 & 2.86 & 0.05 & 0.05 & 0.52 \\
\hline ARP values & 13.53 & 16.69 & 666.67 & 588.24 & 102.04 & 35.21 & 34.97 & 1926.72 & 1941.75 & 192.31 \\
\hline AEAC values & 2345.19 & 2893.41 & & & & 2170.56 & 2154.11 & & & \\
\hline
\end{tabular}

${ }^{\mathrm{a}}$ Mean \pm SD of three replicates. $p<0.05:{ }^{*}$ compared with PCM; ${ }^{5}$ compared with $\mathrm{PCH} ;{ }^{*}$ compared with quercetin; ${ }^{\phi}$ compared with ascorbic acid; ${ }^{\mathrm{b}}$ Phytococktail methanol extract; ${ }^{\mathrm{C} P h y t o c o c k t a i l} \mathrm{n}$-hexane extract; ${ }^{\mathrm{d}}$ Quercetin; ${ }^{\mathrm{e}}$ Ascorbic acid; ${ }^{\mathrm{f}}$ Butylated hydroxytoluene. 


\section{ABTS radical scavenging capacity}

The ABTS radical scavenging capacity (\%) of methanol and n-hexane extracts of the phytococktail compared to QR, AA and BHT has been depicted in Table 1 and the scavenging capacity of the extracts on ABTS radical was similar to the results of the scavenging capacity on DPPH radical. The extracts scavenged the ABTS radical in a dose dependent manner at concentration of 20$500 \mu \mathrm{g} / \mathrm{ml}$. The positive controls viz. QR, AA and BHT at concentration of $2.5-100 \mu \mathrm{g} / \mathrm{ml}$ were also found to produce dose dependent inhibition of ABTS radical. The quantity of methanol and $\mathrm{n}$-hexane extracts required to produce $50 \%$ scavenging $\left(\mathrm{RSa}_{50}\right)$ of ABTS radical were found to be 181.98 and $183.37 \mu \mathrm{g} / \mathrm{ml}$ respectively. Analogous effects were produced by QR, AA and BHT at concentration of 3.42, 3.39 and $33.15 \mu \mathrm{g} / \mathrm{ml}$ respectively. The $\mathrm{EC}_{50}$ and ARP values of the extracts were also comparable to the standards. $\mathrm{EC}_{50}$ values of methanol and n-hexane extracts were found to be 2.84 and $2.86 \mu \mathrm{g} / \mathrm{ml}$ respectively. $\mathrm{QR}, \mathrm{AA}$ and BHT were set up at $\mathrm{EC}_{50}$ of $0.05,0.05$ and 0.52 , respectively. The ARP values of the methanol and n-hexane extracts were 35.21 and 34.97, respectively. AEAC values of methanol and n-hexane extracts were found to be 2170.56 and 2154.11, respectively (Table 1).

\section{Inhibition of lipid peroxidation}

Using egg yolk homogenates as lipid-rich medium of peroxidation, percentage lipid peroxidation inhibition by the phytococktail extracts and the positive controls viz. $\alpha$-tocopherol, BHA and BHT has been shown in Table 2. The $\mathrm{IC}_{50}$ values for methanol, n-hexane, $\alpha$-tocopherol BHA and BHT were 415.54, 29.53, 9.09, 5.57 and 27.01 $\mu \mathrm{g} / \mathrm{ml}$, respectively. Lipid peroxidation inhibitory capacity of the phytococktail extracts was found to increase with increasing concentration and was comparable to the positive standards. The n-hexane extract showed significantly higher inhibition capacity $(p<0.05)$ than the methanol extract. BHA was observed to have significantly higher inhibitory capacity $(p<0.05)$ compared with the methanol, n-hexane extract and the other two standards.

\section{Nitric oxide radical scavenging capacity}

The scavenging capacity of the phytococktail extracts against nitric oxide released by sodium nitroprusside was studied and the result has been depicted in Table 2 . The percentage radical scavenging capacity of the extracts and the reference standard BHA against nitric oxide radical was increased in a dose dependent mode.

Table 2 Effect of phytococktail methanol and $\mathbf{n}$-hexane extracts on lipid peroxide and nitric oxide radical-scavenging capacities $^{\text {a }}$

\begin{tabular}{|c|c|c|c|c|c|c|c|c|}
\hline \multirow{3}{*}{$\begin{array}{l}\text { Concentration } \\
(\mu \mathrm{g} / \mathrm{ml})\end{array}$} & \multicolumn{8}{|c|}{ Inhibition (\%) / Scavenging capacity (\%) } \\
\hline & \multirow[b]{2}{*}{$\mathrm{PCM}^{\mathbf{b}}$} & \multirow[b]{2}{*}{$\mathrm{PCH}^{\mathrm{c}}$} & \multicolumn{3}{|c|}{ Lipid peroxidation inhibition capacity } & \multicolumn{3}{|c|}{ Nitric oxide radical-scavenging capacity } \\
\hline & & & a-tocopherol & $\mathrm{BHA}^{\mathrm{d}}$ & $\mathrm{BHT}^{\mathrm{e}}$ & PCM & $\mathrm{PCH}$ & BHA \\
\hline 2.5 & $21.92 \pm 0.70$ & $29.35 \pm 1.15^{*}$ & $32.19 \pm 2.10^{*}$ & $32.13 \pm 2.17^{*}$ & $24.18 \pm 0.70^{\$ \# \Phi}$ & - & - & $10.29 \pm 0.87$ \\
\hline 5 & $25.11 \pm 0.23$ & $36.65 \pm 0.42^{*}$ & $38.32 \pm 2.13^{*}$ & $54.62 \pm 3.59^{* \text { \$\# }}$ & $30.26 \pm 1.83^{* \$ \# \Phi}$ & - & - & $14.88 \pm 0.29$ \\
\hline 10 & $27.82 \pm 0.50$ & $39.14 \pm 1.01^{*}$ & $56.61 \pm 3.86^{* \$}$ & $68.80 \pm 6.12^{* \$ \#}$ & $32.80 \pm 4.69^{\# \Phi}$ & - & - & $18.74 \pm 0.55$ \\
\hline 15 & $29.55 \pm 0.31$ & $41.97 \pm 0.12^{*}$ & $62.98 \pm 0.38^{* \$}$ & $75.22 \pm 1.00^{* \$ \#}$ & $44.38 \pm 0.48^{* \$ \# \Phi}$ & - & - & $21.89 \pm 0.23$ \\
\hline 20 & $30.07 \pm 0.46$ & $44.13 \pm 2.48^{*}$ & $66.19 \pm 0.55^{* \$}$ & $81.34 \pm 1.09^{* \$ \#}$ & $48.86 \pm 0.64^{* \text { S\#Ф }}$ & $1.18 \pm 0.43$ & $1.18 \pm 0.43$ & $25.54 \pm 0.37^{* \$}$ \\
\hline 40 & $32.38 \pm 0.65$ & $46.92 \pm 0.48^{*}$ & $70.73 \pm 2.05^{* \$}$ & $81.82 \pm 0.71^{* \text { \$\# }}$ & $57.46 \pm 7.40^{* \$ \# \Phi}$ & $3.58 \pm 0.49$ & $2.45 \pm 0.42^{*}$ & $29.10 \pm 0.66^{* \$}$ \\
\hline 50 & $32.38 \pm 0.65$ & $48.25 \pm 0.10^{*}$ & $75.28 \pm 0.99^{* \$}$ & $82.99 \pm 0.30^{* \text { \$\# }}$ & $67.42 \pm 1.97^{* \text { \$\#Ф }}$ & $5.84 \pm 0.43$ & $3.15 \pm 0.49$ & $39.77 \pm 2.67^{* \$}$ \\
\hline 60 & $39.22 \pm 0.10$ & $50.50 \pm 0.42^{*}$ & $79.10 \pm 0.55^{* \$}$ & $87.34 \pm 0.90^{* \text { گ\# }}$ & $79.16 \pm 3.10^{* \$ \Phi}$ & $8.10 \pm 0.65$ & $4.57 \pm 0.43^{*}$ & $42.38 \pm 0.98^{* \$}$ \\
\hline 80 & $42.38 \pm 0.37$ & $54.49 \pm 0.56^{*}$ & $81.22 \pm 0.46^{* \$}$ & $88.12 \pm 1.34^{* \text { \$\# }}$ & $79.70 \pm 1.47^{* \$ \Phi}$ & $11.36 \pm 0.43$ & $5.84 \pm 0.86^{*}$ & $44.89 \pm 0.36^{* \$}$ \\
\hline 100 & $43.41 \pm 0.11$ & $57.16 \pm 0.45^{*}$ & $85.46 \pm 2.28^{* \$}$ & $89.33 \pm 89.33^{* \text { \$\# }}$ & $80.18 \pm 1.14^{* \$ \# \Phi}$ & $13.19 \pm 0.25$ & $7.12 \pm 0.43^{*}$ & $48.12 \pm 1.49^{* \$}$ \\
\hline 150 & $44.56 \pm 0.37$ & $60.61 \pm 0.28^{*}$ & $85.74 \pm 0.19^{* \$}$ & $89.78 \pm 0.21^{* \text { \$\# }}$ & $80.75 \pm 0.20^{* \text { \$\#Ф }}$ & $14.90 \pm 0.65$ & $8.53 \pm 0.24^{*}$ & $50.58 \pm 0.91^{* \$}$ \\
\hline 200 & $45.53 \pm 0.28$ & $62.98 \pm 0.28^{*}$ & $86.57 \pm 0.31^{* \$}$ & 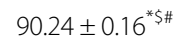 & $81.58 \pm 0.90^{* \$ \# \Phi}$ & $18.15 \pm 0.73$ & $9.38 \pm 0.49^{*}$ & $53.21 \pm 0.65^{* \$}$ \\
\hline 250 & $46.98 \pm 0.46$ & $64.80 \pm 0.21^{*}$ & $86.81 \pm 0.10^{* \$}$ & $90.57 \pm 0.10^{* \text { \$\# }}$ & $82.29 \pm 0.36^{* \$ \# \Phi}$ & $20.83 \pm 1.07$ & $9.94 \pm 0.24^{*}$ & $53.49 \pm 0.14^{* \$}$ \\
\hline 300 & $48.19 \pm 0.32$ & $66.91 \pm 0.48^{*}$ & $87.11 \pm 0.35^{* \$}$ & $90.64 \pm 0.15^{* \text { ऊ\# }}$ & $84.02 \pm 0.50^{* \$ \# \Phi}$ & $23.23 \pm 0.43$ & $10.93 \pm 0.85^{*}$ & $53.85 \pm 0.15^{* \$}$ \\
\hline 400 & $50.74 \pm 0.18$ & $68.43 \pm 0.21^{*}$ & $87.56 \pm 0.33^{* \$}$ & $91.09 \pm 0.70^{* \text { \$\# }}$ & $85.76 \pm 0.42^{* \$ \# \Phi}$ & $25.35 \pm 0.43$ & $12.21 \pm 0.43^{*}$ & $54.19 \pm 0.43^{* \$}$ \\
\hline 500 & $50.74 \pm 0.18$ & $69.58 \pm 0.27^{*}$ & $90.23 \pm 0.66^{* \$}$ & $92.33 \pm 0.38^{* \text { 䩗 }}$ & $88.61 \pm 1.94^{* \$ \Phi}$ & $29.03 \pm 0.88$ & $13.05 \pm 0.43^{*}$ & $56.31 \pm 0.43^{* \$}$ \\
\hline $\mathrm{C}_{50} / \mathrm{RSa}_{50}$ values & 415.54 & 29.53 & 9.09 & 5.57 & 27.01 & 828.87 & 2009.21 & 148.69 \\
\hline
\end{tabular}

${ }^{\mathrm{a}}$ Mean $\pm \mathrm{SD}$ of three replicates. $p<0.05:{ }^{*}$ compared with $\mathrm{PCM} ;{ }^{5}$ compared with $\mathrm{PCH} ;{ }^{\#}$ compared with a-tocopherol; ${ }^{\phi}$ compared with $\mathrm{BHA}$; ${ }^{\mathrm{b}} \mathrm{Phytococktail} \mathrm{methanol}$ extract; ${ }^{\mathrm{C} P h y t o c o c k t a i l} \mathrm{n}$-hexane extract; ${ }^{\mathrm{d}}$ Bulylated hydroxyanisole; ${ }^{\mathrm{e}}$ Butylated hydroxytoluene. 
The $\mathrm{RSa}_{50}$ values for methanol, $\mathrm{n}$-hexane and BHA were 828.87, 2009.21 and $148.69 \mu \mathrm{g} / \mathrm{ml}$, respectively. The methanol extract showed significantly higher radical scavenging capacity $(p<0.05)$ in comparison with the $\mathrm{n}$ hexane extract.

\section{Total antioxidant power (FRAP)}

The ability of the plant extracts to reduce ferric ions was determined using the FRAP assay [41]. An antioxidant capable of donating a single electron to the ferric-TPTZ (Fe(III)-TPTZ) complex would cause the reduction of this complex into the blue ferrous-TPTZ (Fe(II)-TPTZ) complex which absorbs strongly at $593 \mathrm{~nm}$. The FRAP values were found to be $8.21306 \times 10^{-4}$ and $1.03436 \times$ $10^{-3} \mathrm{~mol} \mathrm{Fe}(\mathrm{II}) / \mathrm{g}$ of methanol and n-hexane extract respectively. The FRAP values for the phytococktail extracts were significantly lower than that of $\mathrm{QR}, \mathrm{AA}$ and BHT (Additional file 1: Table S1).

\section{Total polyphenol, flavonoid, flavonol, proanthocyanidin and carotenoid content}

In the present study, the content of total polyphenol in methanol and n-hexane extracts of the phytococktail was found to be $2.3416 \times 10^{-4}$ and $2.899 \times 10^{-4} \mathrm{~mol} / \mathrm{g}$ of extract as expressed in gallic acid equivalent. The concentration of flavonoid in the two extracts was found to be $4.21 \times 10^{-5}$ and $6.11 \times 10^{-5} \mathrm{~mol}$ quercetin/g of extract. The content of flavonol in the phytococktail extracts was $1.068 \times 10^{-4}$ and $9.85 \times 10^{-5} \mathrm{~mol} / \mathrm{g}$ of extract as expressed in quercetin equivalent. Total proanthocyanidin content in the phytococktail extracts was measured to be $3 \times 10^{-7}$ and $2 \times 10^{-7} \mathrm{~mol}$ catechin/g of extract. Quantity of carotenoid in the two extracts was $3.5004 \times 10^{-1}$ and $4.87395 \times$ $10^{-2} \mathrm{mg} / \mathrm{g}$ of extract (Additional file 1: Table S2).

\section{GC/MS chemometric profile of the phytococktail extracts} GC/MS chromatograms of n-hexane and methanol extracts of the phytococktail as per the aforementioned experimental procedure showed various peaks indicating the presence of different chemotypes in the respective extracts.

\section{Methanol extract}

The methanol extract revealed the presence of 19 different chemotypes which were characterized and identified by comparison of their mass fragmentation patterns with those in the NIST database library (Table 3, Figure 1a). Among these 19 chemotypes, $\alpha-\mathrm{D}$-glucopyranoside, $\mathrm{O}-\alpha-$ D-glucopyranosyl-(1.fwdarw.3)- $\beta$-D-fructofuranosyl (53.35\%), 2-furancarboxaldehyde, 5-(hydroxymethyl) (13.17\%), eugenol (7.26\%) and $\tau$-sitosterol (4.31\%) were found to be major constituents whereas, malic acid, dimethyl ester (2.72\%), oleic acid $(2.48 \%)$, 2-methoxynaphthalene (2.46\%), aceteugenol (2.07\%), methyl oleate (1.82\%), 3-hydroxypyridine-N-oxide
(1.67\%), palmitic acid (1.66\%), methyl palmitoleate (1.66\%), methyl palmitate $(1.43 \%)$, piperine $(1.24 \%)$, palmitoleic acid (1.07\%), 1-methyl-4-hydroxybenzoate (0.81\%), stigmastanol (0.71\%), trans-caryophyllene $(0.29 \%)$ and $\alpha$-tocopherol $(0.22 \%)$ were found to be present in trace amount.

\section{n-Hexane extract}

GC/MS chemometric profile of the phytococktail n-hexane extract showed the presence of 21 different chemotypes (Table 4, Figure 1b). Among these 21 chemotypes, eugenol (41.93\%), piperine (10.87\%), aceteugenol (8.28\%), trans-caryophyllene (8.41\%) and $\tau$-sitosterol $(6.62 \%)$ were found to be present in major amount whereas, $\delta$-cadinene $(3.08 \%)$, isoledene $(2.55 \%)$, cuminic aldehyde $(2.46 \%)$, calamenene $(2.44 \%), \alpha$-tocopherol $(1.55 \%)$, $\alpha$-levantenolide (1\%), $\alpha$-humulene $(0.96 \%), \quad$ cedr- 8 -ene (0.91\%), $\alpha$-muurolene $(0.81 \%)$, bis(2-ethylhexyl)phthalate (0.69\%), 3-methoxy-5-methylphenol (0.43\%), ar-curcumene (0.61\%), $\alpha$-amorphene $(0.40 \%)$, caryophyllene oxide $(0.36)$ and 1,3-bis(cinnamoyloxymethyl)adamantane (0.29\%) were found to be present in trace amount.

\section{Discussion}

Progression of a large number of common chronic diseases is induced by free radical-mediated oxidative damage and a lot of health benefits are attributed to the utilization of fruits and vegetables in our diet due to their strong antioxidant capacities. A wide variety of biologically active phytochemicals such as polyphenols, flavonoids, alkaloids, terpenoids, carotenoids etc. are derived from plant foods and natural products which have promising health benefits. These diverse phytocompounds have protective effects against chronic diseases while acting in combination rather than individually [47]. In recent times, the antioxidant content has become an essential biochemical marker of plant product quality. The antioxidant capacity resulting from hydrophilic or lipophilic compounds individually has been estimated in plant foods. In the present work, we have performed the widely used and well recognized antioxidant capacity assays that have positive influence and applications in biological antioxidant research. The DPPH radical scavenging assay is a simple and precise method to measure the antioxidant capacity of plant extracts where the DPPH radical is used as a stable free radical to determine the antioxidant capacity of natural compounds. In our study, the DPPH radical scavenging capacity of the phytococktail extracts was found to increase in a dose dependent manner. The phytococktail extracts at the used concentrations displayed potential free radicals scavenging effect (Table 1). A higher DPPH radical scavenging capacity is associated with a lower $\mathrm{RSa}_{50}$ value. The DPPH radical is considered as a model for lipophilic radical and from our result, it is evident that the phytococktail n-hexane extract showed significantly higher 
Table 3 Chemometric profile of methanol extract of phytococktail

\begin{tabular}{|c|c|c|c|c|c|c|c|c|c|c|c|c|c|}
\hline S. No. & $\begin{array}{l}\text { Peak RT } \\
(\mathrm{min})\end{array}$ & Peak area & Peak area (\%) & Compound detected & Major group & Hit & SI & RSI & Prob & CAS No & $\begin{array}{l}\text { Mol. } \\
\text { formula }\end{array}$ & Mol. Wt. & $\begin{array}{l}\text { Content } \\
(\mathrm{mg} / \mathrm{g})\end{array}$ \\
\hline 1 & 6.48 & 4314646 & 1.67 & 3-Hydroxypyridine-N-oxide & Alkaloid derivative & 1 & 664 & 887 & 46.53 & $6602-28-4$ & $\mathrm{C}_{5} \mathrm{H}_{5} \mathrm{NO}_{2}$ & 111 & 0.0501 \\
\hline 2 & 9.81 & 7021309 & 2.72 & Malic acid, dimethyl ester & Organic acid ester & 1 & 717 & 821 & 22.44 & $1587-15-1$ & $\mathrm{C}_{6} \mathrm{H}_{10} \mathrm{O}_{5}$ & 162 & 0.0816 \\
\hline 3 & 10.07 & 6345493 & 2.46 & 2-Methoxynaphthalene & Aromatic ether & 1 & 702 & 709 & 50.19 & $93-04-9$ & $\mathrm{C}_{11} \mathrm{H}_{10} \mathrm{O}$ & 158 & 0.0738 \\
\hline 4 & 12.03 & 33982819 & 13.17 & 2-Furancarboxaldehyde, 5-(hydroxymethyl) & Aldehyde & 1 & 735 & 800 & 85.35 & $67-47-0$ & $\mathrm{C}_{6} \mathrm{H}_{6} \mathrm{O}_{3}$ & 126 & 0.3951 \\
\hline 5 & 13.90 & 18735029 & 7.26 & Eugenol & Phenylpropanoid & 1 & 861 & 884 & 29.07 & $97-53-0$ & $\mathrm{C}_{10} \mathrm{H}_{12} \mathrm{O}_{2}$ & 164 & 0.2178 \\
\hline 6 & 15.05 & 731414 & 0.29 & trans-Caryophyllene & Terpenoid & 1 & 742 & 829 & 4.78 & $87-44-5$ & $\mathrm{C}_{15} \mathrm{H}_{24}$ & 204 & 0.0087 \\
\hline 7 & 15.97 & 2081450 & 0.81 & 1-Methyl-4-hydroxybenzoate & Organic acid ester & 1 & 636 & 790 & 18.25 & $99-76-3$ & $\mathrm{C}_{8} \mathrm{H}_{8} \mathrm{O}_{3}$ & 152 & 0.0243 \\
\hline 8 & 16.47 & 5342706 & 2.07 & Aceteugenol acetate & Phenylpropanoid derivative & 3 & 836 & 852 & 18.05 & $93-28-7$ & $\mathrm{C}_{12} \mathrm{H}_{14} \mathrm{O}_{3}$ & 206 & 0.0621 \\
\hline 9 & 19.21 & 137973198 & 53.35 & $\begin{array}{l}\text { a-D-glucopyranoside, } \\
\text { O-a-D-glucopyranosyl-(1.fwdarw.3)- } \beta \text {-D-fructofuranosyl }\end{array}$ & Glycoside & 1 & 696 & 704 & 16.21 & $597-12-6$ & $\mathrm{C}_{18} \mathrm{H}_{32} \mathrm{O}_{16}$ & 504 & 1.6005 \\
\hline 10 & 21.89 & 4275714 & 1.66 & Methyl palmitoleate & Fatty acid ester & 1 & 837 & 843 & 54.57 & $1120-25-8$ & $\mathrm{C}_{17} \mathrm{H}_{32} \mathrm{O}_{2}$ & 268 & 0.0498 \\
\hline 11 & 22.16 & 3692581 & 1.43 & Methyl palmitate & Fatty acid ester & 1 & 769 & 807 & 66.81 & $112-39-0$ & $\mathrm{C}_{17} \mathrm{H}_{34} \mathrm{O}_{2}$ & 270 & 0.0429 \\
\hline 12 & 22.42 & 2765978 & 1.07 & Palmitoleic acid & Fatty acid & 1 & 783 & 800 & 58.89 & 2091-29-4 & $\mathrm{C}_{16} \mathrm{H}_{30} \mathrm{O}_{2}$ & 254 & 0.0321 \\
\hline 13 & 22.66 & 4283613 & 1.66 & Palmitic acid & Fatty acid & 1 & 765 & 800 & 58.65 & $57-10-3$ & $\mathrm{C}_{16} \mathrm{H}_{32} \mathrm{O}_{2}$ & 256 & 0.0498 \\
\hline 14 & 24.29 & 4700456 & 1.82 & Methyl oleate & Fatty acid ester & 1 & 779 & 809 & 15.15 & $112-62-9$ & $\mathrm{C}_{19} \mathrm{H}_{36} \mathrm{O}_{2}$ & 296 & 0.0546 \\
\hline 15 & 24.79 & 6407869 & 2.48 & Oleic acid & Fatty acid & 1 & 758 & 775 & 20.74 & $112-80-1$ & $\mathrm{C}_{18} \mathrm{H}_{34} \mathrm{O}_{2}$ & 282 & 0.0744 \\
\hline 16 & 33.27 & 3211489 & 1.24 & Piperine & Alkaloid & 1 & 603 & 733 & 69.74 & $94-62-2$ & $\mathrm{C}_{17} \mathrm{H}_{19} \mathrm{NO}_{3}$ & 285 & 0.0372 \\
\hline 17 & 36.49 & 558710 & 0.22 & a-Tocopherol & Phytosterol & 1 & 649 & 715 & 64.90 & $59-02-9$ & $\mathrm{C}_{29} \mathrm{H}_{50} \mathrm{O}_{2}$ & 430 & 0.0066 \\
\hline 18 & 39.10 & 11115657 & 4.31 & T-Sitosterol & Phytosterol & 2 & 691 & 762 & 34.65 & $83-47-6$ & $\mathrm{C}_{29} \mathrm{H}_{50} \mathrm{O}$ & 414 & 0.1293 \\
\hline 19 & 41.47 & 794822 & 0.31 & Unknown & - & - & - & - & - & - & - & - & 0.0093 \\
\hline
\end{tabular}



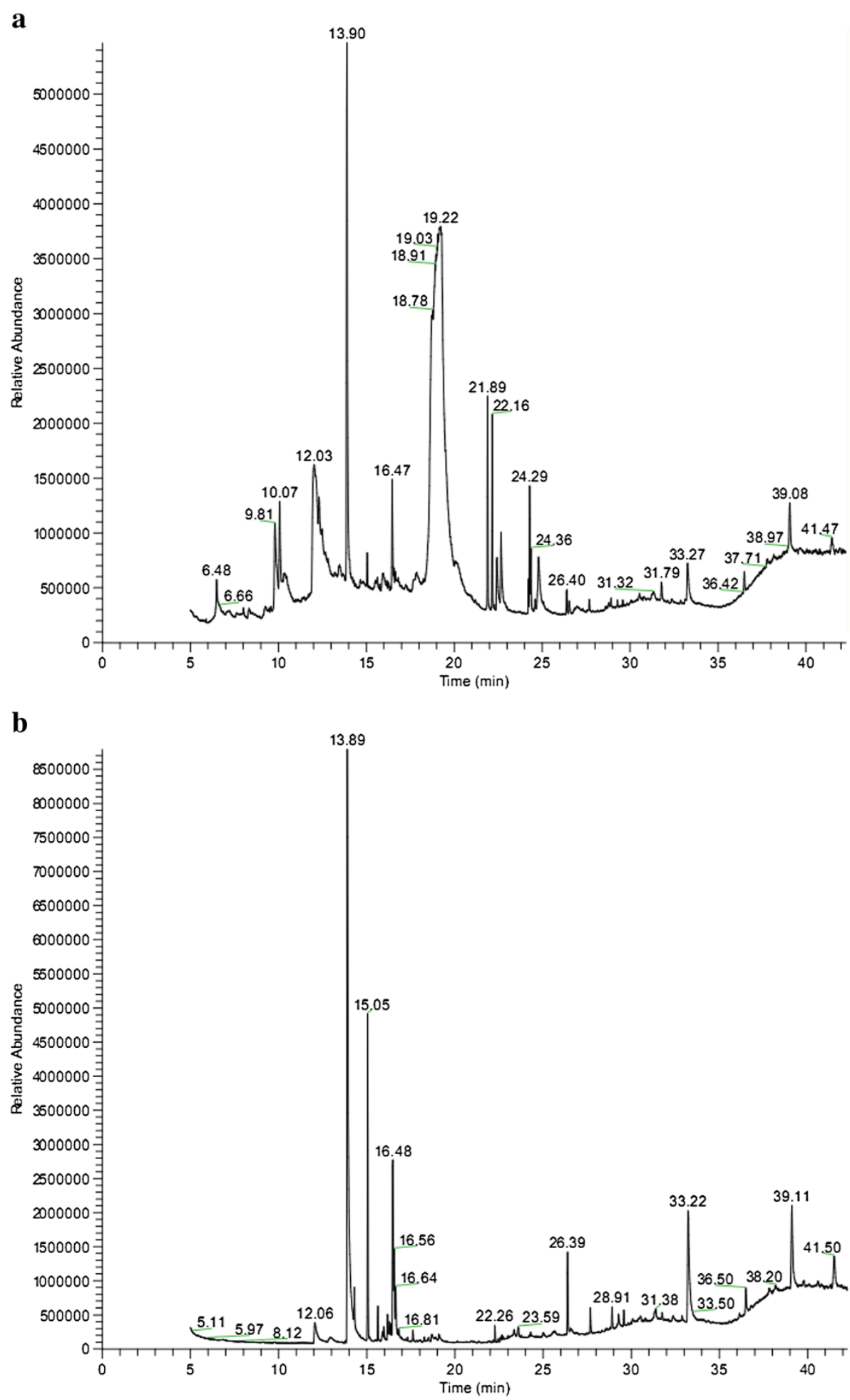

Figure $1 \mathrm{GC} / \mathrm{MS}$ chromatogram of phytococktail a. methanol extract, b. $\mathrm{n}$-hexane extract.

$(p<0.05)$ inhibition of DPPH radical as compared to methanol extract at concentration of $20-300 \mu \mathrm{g} / \mathrm{ml}$. This result may be due to the activity of higher amount of lipophilic antioxidants present in the $\mathrm{n}$-hexane extract in comparison with methanol extract. The ABTS assay is of great relevance to the study of both hydrophilic and lipophilic antioxidants as well as pure compounds and food extracts [38]. The antioxidant capacity measured by ABTS 


\begin{tabular}{|c|c|c|c|c|c|c|c|c|c|c|c|c|c|}
\hline S. No. & Peak RT (min) & Peak area & Peak area (\%) & Compound detected & Major group & Hit & SI & RSI & Prob & CAS No & Mol. formula & Mol. Wt. & Content $(\mathrm{mg} / \mathrm{g})$ \\
\hline 1 & 12.06 & 2819064 & 2.46 & Cuminic aldehyde & Aromatic aldehyde & 3 & 793 & 856 & 22.00 & $122-03-2$ & $\mathrm{C}_{10} \mathrm{H}_{12} \mathrm{O}$ & 148 & 0.0246 \\
\hline 2 & 12.92 & 335612 & 0.29 & $\begin{array}{l}\text { 1,3-Bis(cinnamoyloxymethyl) } \\
\text { adamantane }\end{array}$ & Ether & 2 & 712 & 723 & 19.29 & $303797-58-2$ & $\mathrm{C}_{30} \mathrm{H}_{32} \mathrm{O}_{4}$ & 456 & 0.0029 \\
\hline 3 & 13.89 & 48606490 & 41.93 & Eugenol & Phenylpropanoid & 1 & 877 & 879 & 18.05 & $97-53-0$ & $\mathrm{C}_{10} \mathrm{H}_{12} \mathrm{O}_{2}$ & 164 & 0.4193 \\
\hline 4 & 14.29 & 2923628 & 2.55 & Isoledene & Terpenoid & 1 & 707 & 721 & 14.90 & $95910-36-4$ & $\mathrm{C}_{15} \mathrm{H}_{24}$ & 204 & 0.0255 \\
\hline 5 & 15.05 & 9616594 & 8.41 & trans-Caryophyllene & Terpenoid & 1 & 862 & 866 & 13.91 & $87-44-5$ & $\mathrm{C}_{15} \mathrm{H}_{24}$ & 204 & 0.0841 \\
\hline 6 & 15.63 & 1104181 & 0.96 & a-Humulene & Terpenoid & 1 & 821 & 837 & 9.62 & 6753-98-6 & $\mathrm{C}_{15} \mathrm{H}_{24}$ & 204 & 0.0096 \\
\hline 7 & 15.90 & 458653 & 0.40 & a-Amorphene & Terpenoid & 1 & 763 & 841 & 5.04 & 23515-88-0 & $\mathrm{C}_{15} \mathrm{H}_{24}$ & 204 & 0.004 \\
\hline 8 & 15.97 & 697731 & 0.61 & ar-Curcumene & Terpenoid & 1 & 785 & 801 & 71.73 & $644-30-4$ & $\mathrm{C}_{15} \mathrm{H}_{22}$ & 202 & 0.0061 \\
\hline 9 & 16.18 & 1038187 & 0.91 & Cedr-8-ene & Terpenoid & 1 & 799 & 805 & 9.62 & $469-61-4$ & $\mathrm{C}_{15} \mathrm{H}_{24}$ & 204 & 0.0091 \\
\hline 10 & 16.27 & 927957 & 0.81 & a-Muurolene & Terpenoid & 1 & 821 & 850 & 7.06 & $31983-22-9$ & $\mathrm{C}_{15} \mathrm{H}_{24}$ & 204 & 0.0081 \\
\hline 11 & 16.48 & 9478971 & 8.28 & Aceteugenol & Phenylpropanoid & 1 & 864 & 873 & 19.60 & $93-28-7$ & $\mathrm{C}_{12} \mathrm{H}_{14} \mathrm{O}_{2}$ & 206 & 0.0828 \\
\hline 12 & 16.56 & 3528046 & 3.08 & $\delta$-Cadinene & Terpenoid & 1 & 760 & 853 & 19.23 & $483-76-1$ & $\mathrm{C}_{15} \mathrm{H}_{24}$ & 204 & 0.0308 \\
\hline 13 & 16.64 & 2791591 & 2.44 & Calamenene & Terpenoid & 6 & 642 & 699 & 8.58 & $483-77-2$ & $\mathrm{C}_{15} \mathrm{H}_{22}$ & 202 & 0.0244 \\
\hline 14 & 17.62 & 413127 & 0.36 & Caryophyllene oxide & Terpenoid & 1 & 789 & 812 & 39.62 & $1139-30-6$ & $\mathrm{C}_{15} \mathrm{H}_{24} \mathrm{O}$ & 220 & 0.0036 \\
\hline 15 & 26.39 & 3168547 & 2.77 & Unknown & - & - & - & - & - & - & - & - & 0.0277 \\
\hline 16 & 27.68 & 1134640 & 1.00 & a-Levantenolide & Terpenoid & 1 & 620 & 728 & 55.67 & $30987-48-5$ & $\mathrm{C}_{20} \mathrm{H}_{30} \mathrm{O}_{3}$ & 318 & 0.01 \\
\hline 17 & 28.91 & 791295 & 0.69 & Bis(2-ethylhexyl)phthalate & Ester & 1 & 685 & 741 & 13.24 & 117-81-7 & $\mathrm{C}_{24} \mathrm{H}_{38} \mathrm{O}_{4}$ & 390 & 0.0069 \\
\hline 18 & 33.22 & 12440863 & 10.87 & Piperine & Alkaloid & 1 & 753 & 815 & 86.19 & $94-62-2$ & $\mathrm{C}_{17} \mathrm{H}_{19} \mathrm{NO}_{3}$ & 285 & 0.1087 \\
\hline 19 & 36.50 & 1764098 & 1.55 & a-Tocopherol & Phytosterol & 1 & 683 & 728 & 39.19 & $59-02-9$ & $\mathrm{C}_{29} \mathrm{H}_{50} \mathrm{O}_{2}$ & 430 & 0.0155 \\
\hline 20 & 39.11 & 7572383 & 6.62 & T-Sitosterol & Phytosterol & 1 & 768 & 807 & 64.55 & $83-47-6$ & $\mathrm{C}_{29} \mathrm{H}_{50} \mathrm{O}$ & 414 & 0.0662 \\
\hline 21 & 41.50 & 3433999 & 3.01 & Unknown & - & - & - & - & - & - & - & - & 0.0301 \\
\hline
\end{tabular}


assay was determined by the decolorization of $\mathrm{ABTS}^{+}$, by measuring the reduction of radical cation as percentage inhibition of absorbance at $734 \mathrm{~nm}$. The results of ABTS assay revealed the same phenomenon where the n-hexane extract showed significantly higher $(p<0.05)$ radical scavenging property than methanol extract at 20,40, 150 and $250 \mu \mathrm{g} / \mathrm{ml}$ concentrations. For measuring the $\mathrm{RSa}_{50}$ values accurately, we took a long concentration range (from very low to very high concentration) of the test materials. In contrast to the more direct methods for measuring antioxidant capacities of plant extracts, the FRAP assay is derived from a different redox reaction and due to its low cost, rapidity and technical simplicity, it has become a valuable method for detecting total antioxidant/reducing power of plant extracts. It has also been proven to produce values that have positive correlation with the results achieved by direct antioxidant capacity assays for various phytofoods [48]. Both extracts of the phytococktail were found to have high FRAP values which signify their high antioxidant potential. Our results are in agreement with the previous findings, where antioxidant capacity assays using DPPH', ABTS $^{+}$and FRAP exhibited analogous results [49].

In oxidative stress condition, intracellular and membrane lipids lose a hydrogen atom from an unsaturated fatty acyl chain and initiate lipid peroxidation that propagates as a chain reaction to generate a diverse array of peroxides and cyclic endoperoxides that produce a pink chromogen on reaction with thiobarbituric acid with highest absorbance at $532 \mathrm{~nm}$, thus provide an estimate of lipid peroxidation inhibition [50]. Lipid peroxidation leads to an elevated oxidative stress in cells and induces numerous pathophysiological processes for disease development. Hence, inhibition of lipid peroxidation is a crucial property of the antioxidants present in plant extract by which they can alleviate the oxidative stress induced diseases [51]. In our study, the n-hexane extract displayed high inhibitory capacity which may be due to the presence of lipophilic antioxidants in this extract. The methanol extract also exhibited lipid peroxidation inhibition property. Thus, it can be assumed that the methanol and n-hexane extracts of the phytococktail could be beneficial in preventing the oxidative damage and uphold the cellular, structural and functional integrity in stressful environments.

Nitric oxide plays vital role in the pathogenesis of several inflammatory diseases and other health problems [52]. In aqueous solution (with physiological $\mathrm{pH}$ ) nitric oxide radical is generated from sodium nitroprusside and reacts with oxygen to form nitrogen oxide radicals which are scavenged by plant extracts through direct competition with oxygen and other oxides in the reaction medium [53]. In the present investigation, both n-hexane and methanol extracts of the phytococktail showed potential antioxidant capacity by scavenging the nitric oxide radicals. Therefore, the phytococktail could be useful in ameliorating a large number of diseases caused by inflammation and cellular damage.

The phenolic compounds derived from plants are known to be powerful chain breaking natural antioxidants. The use of phenolics in the food industry is increasing because they retard oxidative degradation of lipids and thereby improve the quality and nutritional value of food. Flavonoids are natural phenolic compounds and well known antioxidants. In various studies, the plant extracts rich in flavonoids were found to have high antioxidant capacity. Flavonols are the major class of flavonoids present in a variety of fruits and vegetables and possess high antioxidant and antiradical capacity with many therapeutic applications $[54,55]$. Plant fruits contain carotenoids that also play an important role in human diet with their ability to act as free radical scavengers. The most widespread secondary metabolites in the plant kingdom reported so far are the phenolics and they have received great attention as potential natural antioxidant in terms of their ability to act as both efficient radical scavengers and metal chelator. Our results are in agreement with previous studies that showed significant positive correlation between total phenolic contents and antioxidant capacities of plant extracts [56]. From our results of phytochemical constituents present in the phytococktail (Additional file 1: Table S2, Figure 2), it is apparent that the antioxidant capacities of the phytococktail methanol extract can be attributed mainly to total polyphenol, flavonol, proanthocyanidin, glycoside, aldehyde and phenylpropanoid whereas, the antioxidant capacities of $\mathrm{n}$-hexane extract can primarily be ascribed to total polyphenol, flavonoid, carotenoid, phenylpropanoid, terpenoid and alkaloid content. Therefore, the presence of these lipophilic and hydrophilic antioxidants identified during the phytochemical characterization could have contributed to the high antioxidant capacities of the extracts. The results of correlation analysis suggest that all the antioxidant capacity assays were significantly ( $p \leq$ $0.05, p \leq 0.01$ ) associated with the total contents of different bioactive compounds in the phytococktail extracts (Additional file 1: Table S3). The berries of sea buckthorn have been well reported to contain a significant amount of natural antioxidants [17]. These were the prime raw ingredient of the phytococktail and may contribute to the total antioxidant capacity. In addition, apricot and roseroot also possess a diverse array of bioactive compounds [6,18-20] which could be responsible for the elevated antioxidant properties of the phytococktail extracts.

We have determined the bioactive volatile and semivolatile components in the phytococktail by GC/MS chemometric profiling. In medicinal chemistry it is very 


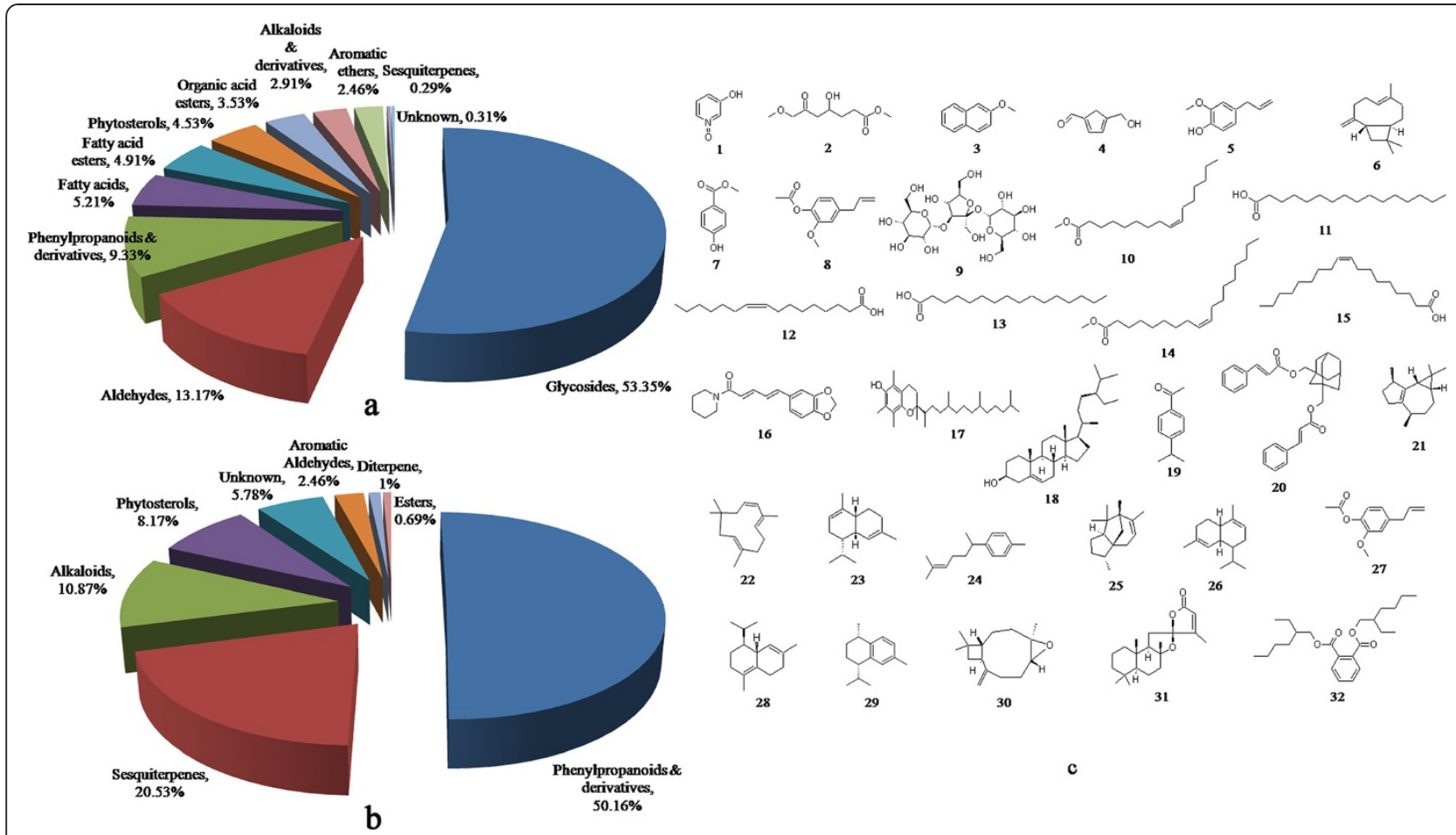

Figure 2 Major phytochemical groups in phytococktail extracts. a. methanol extract, $\mathbf{b}$. n-hexane extract. c. phyto-chemotypes identified in methanol and n-hexane extracts of phytococktail.1: 3-Hydroxypyridine-N-oxide; 2: Malic acid, dimethyl ester; 3: 2-Methoxynaphthalene; 4: 2-Furancarboxaldehyde, 5-(hydroxymethyl); 5: Eugenol; 6: trans-Caryophyllene; 7: 1-Methyl-4-hydroxybenzoate; 8: Aceteugenol acetate; 9: a-Dglucopyranoside, O-a-D-glucopyranosyl-(1.fwdarw.3)-B-D-fructofuranosyl; 10: Methyl palmitoleate; 11: Methyl palmitate; 12: Palmitoleic acid; 13: Palmitic acid; 14: Methyl oleate; 15: Oleic acid; 16: Piperine; 17: a-Tocopherol; 18: T-Sitosterol; 19: Cuminic aldehyde; 20: 1,3-Bis(cinnamoyloxymethyl) adamantane; 21: Isoledene; 22: a-Humulene; 23: a-Amorphene; 24: ar-Curcumene; 25: Cedr-8-ene; 26: a-Muurolene; 27: Aceteugenol; 28: $\delta$-Cadinene; 29: Calamenene; 30: Caryophyllene oxide; 31: a-Levantenolide; 32: Bis(2-ethylhexyl)phthalate.

essential to ascertain the chemotyping of natural products that will allow us to scientifically determine and validate their traditional uses, pharmacological activities and therapeutic potential. Among the total compounds analysed by GC/MS, phenylpropanoids and their derivatives $(59.49 \%)$ was the major cluster found in the n-hexane extract followed by sesquiterpenes (20.53\%), alkaloids and derivatives (10.87\%) and phytosterols (8.17\%). In methanol extract glycosides (53.35\%) was present in major amount followed by aldehydes (13.17\%), phenylpropanoid derivatives (9.33\%), fatty acids (5.21\%), fatty acid esters (4.91\%), phytostrerols (4.53\%), organic acid esters (3.53\%) and alkaloids and derivatives (2.91\%). Relative abundance of major compounds in methanol and $\mathrm{n}$-hexane extracts has been illustrated in Additional file 2: Figure S1 and Additional file 3: Figure S2. The order of extraction capacities of different polarity solvents for phenylpropanoids and derivatives, phytosterols, alkaloids and derivatives and sesquiterpenes was as follows: phenylpropanoids and derivatives: methanol (9.33\%), n-hexane (50.16\%); phytosterols: methanol (4.53\%), n-hexane (8.17\%); alkaloids and derivatives: methanol (2.91\%), n-hexane (10.87\%); sesquiterpenes: methanol (0.29\%), n-hexane
(20.53\%) (Figure 2). All these compounds identified by GC/ MS analysis were further investigated for their biological activities in Dr. Duke's Phytochemical and Ethnobotanical Databases [57] which revealed that they possess a diverse range of positive pharmacological actions (Additional file 1: Table S4). Eventually, in the present study we have found glycosides, phenylpropanoids and derivatives, terpenoids, alkaloids, phytosterols, fatty acids and esters as the major groups of phyto-chemotypes in the extracts which are extremely beneficial for improving human health. These compounds have a broad range of pharmacological and therapeutic potential and could also be responsible for the high antioxidant capacities of the phytococktail.

In the present work it was established that the phytococktail extracts contained a considerable amount of diverse bioactive compounds with high antioxidant capacities. A significant and linear correlation was established between the antioxidant capacities and bioactive principles, demonstrating that these compounds could be the major contributors to antioxidant capacities. A total of 32 phyto-chemotypes have been identified from the methanol and $n$-hexane extracts of the phytococktail by GC/MS (Figure 2c). However, isolation of individual 
phyto-chemotypes and subjecting them to biological activity will definitely give fruitful results which may lead to the development of a novel drug.

\section{Conclusion}

The phytococktail extracts contain various bioactive chemotypes having pharmaceutical importance and antioxidant properties. The phytococktail can definitely be used as an alternative source of natural antioxidants with consequential health promoting effects in the oxidative stress conditions. As a whole, it can be concluded that the phytococktail could be an aid in the stressful environment of high altitude as it conduce the maximum health benefit under a number of pattern of antioxidant capacity.

\section{Additional files}

Additional file 1: Table S1. Ferric reducing antioxidant power (FRAP) of phytococktail methanol and n-hexane extracts ${ }^{\text {a }}$. Table S2. Estimation of phytotochemical contents of phytococktail methanol and n-hexane extracts ${ }^{a}$. Table S3. Pearson's correlation coefficients between bioactive phyto-compounds and antioxidant capacity of $\mathrm{PCM}^{\mathrm{a}}$ and $\mathrm{PCH}^{\mathrm{b}}$. Table S4. Biological activities of active principles present in phytococktail extracts.

Additional file 2: Figure S1. Relative abundance of major compounds in methanol extract. a. 2-Furancarboxaldehyde, 5-(hydroxymethyl)- , b. Eugenol, c. a-D-glucopyranoside, O-a-D-glucopyranosyl-(1.fwdarw.3)- $\beta$-Dfructofuranosyl, d. T-Sitosterol.

Additional file 3: Figure S2. Relative abundance of major compounds in n-hexane extract. a. Eugenol, b. trans-Caryophyllene, c. Aceteugenol, d. Piperine.

\section{Competing interests}

The authors declare that they have no competing interests.

\section{Authors' contributions}

$P D, P K B, A B T, O P C$ and SBS conceived and designed the experiments. PD, $P K B$ and $A B T$ performed the experiments and analyzed the data. PD, PKB and $A B T$ contributed reagents/materials/analysis tools. PD and ABT wrote the manuscript. OPC, RBS and SBS did the concise review. All authors read and approved the final manuscript.

\section{Acknowledgement}

The study was fully supported by Defence Research and Development Organisation (DRDO), Ministry of Defence, Government of India. The authors acknowledge the contribution of Ritendra Mishra, DIHAR, DRDO and Debasmita Ghosh, Maharaja Manindra Chandra College, Kolkata who helped in copyediting and proofreading of the manuscript.

\section{Author details}

'Defence Institute of High Altitude Research, Defence Research \& Development Organisation, C/o 56 APO, Leh-Ladakh, Jammu \& Kashmir, Pin 901205, India. ${ }^{2}$ Defence Institute of Physiology and Allied Sciences, Defence Research \& Development Organisation, Lucknow Road, Timarpur, Delhi, Pin 110054, India.

Received: 10 May 2013 Accepted: 23 September 2013

Published: 7 October 2013

\section{References}

1. Aruoma Ol: Free radicals, oxidative stress, and antioxidants in human health and disease. J Am Oil Chem Soc 1998, 75:199-212.

2. Gosslau A, Chen KY: Nutraceuticals, apoptosis, and disease prevention. Nutrition 2004, 20:95-102.
3. Podsędek A: Natural antioxidants and antioxidant capacity of brassica vegetables: a review. LWT 2007, 40:1-11.

4. Korekar G, Stobdan T, Singh H, Chaurasia OP, Singh SB: Phenolic content and antioxidant capacity of various solvent extracts from seabuckthorn (Hippophae rhamnoides L.) fruit pulp, seeds, leaves and stem bark. Acta Aliment Hung 2011, 40:49-458.

5. Korekar G, Stobdan T, Arora R, Yadav A, Singh SB: Antioxidant capacity and phenolics content of apricot (Prunus armeniaca L.) kernel as a function of genotype. Plant Foods Hum Nutr 2012, 66:376-383.

6. Tayade AB, Dhar P, Sharma M, Chauhan RS, Chaurasia OP, Srivastava RB: Antioxidant capacities, phenolic contents, and GC/MS analysis of Rhodiola imbricata Edgew. root extracts from Trans-Himalaya. J Food Sci 2013, 78:402-410.

7. Maestri DM, Nepote $\mathrm{V}$, Lamarque AL, Zygadlo JA: Natural products as antioxidants. In Phytochemistry: Advances in Research. T.C. 37/661(2). Edited by Imperato F. Trivandrum: Research Signpost; 2006:105-135.

8. lordache A, Culea M, Gherman C, Cozar O: Characterization of some plant extracts by GC-MS. Nucl Instrum Meth B 2009, 267:338-342.

9. Schoene RB: Physical performance at high altitude. In Nutritional needs in cold and high altitude environment - Applications for military personnel in field operations. Edited by Bernadette MM, Sydne JC. Washington DC: National Academy Press; 1996:319-330.

10. Dang S, Yan H, Yamamoto S, Wang $X$, Zeng L: Poor nutritional status of younger Tibetan children living at high altitudes. Eur J Clin Nutr 2004, 58:938-946

11. Sherpa LY, Deji, Stigum H, Chongsuvivatwong V, Nafstad P, Bjertness E: Prevalence of metabolic syndrome and common metabolic components in high altitude farmers and herdsmen at $3700 \mathrm{~m}$ in Tibet. High Alt Med Biol 2013, 14:37-44.

12. Ballabh B, Chaurasia OP, Ahmed Z: Herbal products from high altitude plants of Ladakh Himalaya. Curr Sci 2007, 92:1664-1665.

13. Stobdan T, Singh SB: Gold mine of the cold desert. Sci Rep 2009, 46:39-41.

14. Malik SK, Chaudhury R, Dhariwal OP, Mir S: Genetic diversity and traditional uses of wild apricot (Prunus armeniaca L.) in high-altitude north-western Himalayas of India. Plant Genet Resour 2010, 8:249-257.

15. Dwivedi SK, Kareem A, Ahmed Z: Apricot in Ladakh. Delhi: DESIDOC, DRDO; 2007.

16. Chaurasia OP, Ballabh B, Singh B: Himalayan rose root, Rhodiola spp.potential health drink and drug plant. Nat Prod Rad 2003, 2:71-92.

17. Suryakumar G, Gupta A: Medicinal and therapeutic potential of Sea buckthorn (Hippophae rhamnoides L.). J Ethnopharmacol 2011, 138:268-278.

18. Erdogan-Orhan I, Kartal M: Insights into research on phytochemistry and biological activities of Prunus armeniaca L. (Apricot). Food Res Int 2011, 44:1238-1243.

19. Tayade AB, Dhar P, Kumar J, Sharma M, Chauhan RS, Chaurasia OP, Srivastava RB: Chemometric profile of root extracts of Rhodiola imbricata Edgew. with hyphenated gas chromatography mass spectrometric technique. PLoS One 2013a, 8:e52797.

20. Tayade AB, Dhar P, Kumar J, Sharma M, Chaurasia OP, Srivastava RB: Sequential determination of fat- and water-soluble vitamins in Rhodiola imbricata root from trans-Himalaya with rapid resolution liquid chromatography/tandem mass spectrometry. Anal Chim Acta 2013c, 789:65-73.

21. Ali R, Ali R, Jaimini A, Nishad DK, Mittal G, Chaurasia OP, Kumar R, Bhatnagar A, Singh SB: Acute and sub acute toxicity and efficacy studies of Hippophae rhamnoides based herbal antioxidant supplement. Ind J Pharmacol 2012, 44:504-508.

22. Gupta V, Saggu S, Tulsawani RK, Sawhney RC, Kumar R: A dose dependent adaptogenic and safety evaluation of Rhodiola imbricata Edgew, a high altitude rhizome. Food Chem Toxicol 2008, 46:1645-1652.

23. Hegedus A, Engel R, Abrankó L, Balogh E, Blázovics A, Hermán R, Halász J, Ercisli S, Pedryc A, Stefanovits-Bányai É: Antioxidant and antiradical capacities in apricot (Prunus armeniaca L.) fruits: variations from genotypes, years, and analytical methods. J Food Sci 2010, 75:722-730.

24. Yurt B, Celik I: Hepatoprotective effect and antioxidant role of sun, sulphited-dried apricot (Prunus armeniaca L.) and its kernel against ethanolinduced oxidative stress in rats. Food Chem Toxicol 2011, 49:508-513.

25. Yadav A, Stobdan T, Dwivedi SK, Korekar G, Targais K, Srivastava RB: Apricot (Prunus armeniaca L.) for livelihood security in cold deserts. In Innovations in Agro Animal Technologies. Edited by Srivastava RB, Selvamurthy W. Delhi: Satish Serial Publishing House; 2011:87-97. 
26. Chaurasia OP, Hota SK, Kumar R, Tayade AB, Srivastava RB: Trans-Himalayan Medicinal Plants and Herbal Nutraceutical Products. In Innovations in Agro Animal Technologies. Edited by Srivastava RB, Selvamurthy W. Delhi: Satish Serial Publishing House; 2011:113-129.

27. Kala CP: Medicinal plants of the high altitude cold desert in India; Diversity, distribution and traditional uses. Int J Biodivers Sci Manag 2006, 2:43-56.

28. Chaurasia OP, Ahmed Z, Ballabh B: Ethnobotany and Plants of Trans-Himalaya. Delhi, India: Satish Serial Publishing House; 2007.

29. Gupta R, Flora SJ: Protective effects of fruit extracts of Hippophae rhamnoides L. against arsenic toxicity in Swiss albino mice. Hum Exp Toxicol 2006, 25:285-295

30. Kim YK, Koo BS, Gong DJ, Lee YC, Ko JH, Kim CH: Comparative effect of Prunus persica L. BATSCH-water extract and tacrine (9-amino-1,2,3,4 tetrahydroacridine hydrochloride) on concentration of extracellular acetylcholine in the rat hippocampus. J Ethnopharmacol 2003, 87:149-154.

31. Perfumi M, Mattioli L: Adaptogenic and central nervous system effects of single doses of $3 \%$ rosavin and $1 \%$ salidroside Rhodiola rosea L. extract in mice. Phytother Res 2007, 21:37-43.

32. Liyana-Pathiranan CM, Shahidi F: Antioxidant activity of commercial soft and hard wheat (Triticum aestivum L.) as affected by gastric $\mathrm{pH}$ conditions. J Agric Food Chem 2005, 53:2433-2440.

33. Teke GN, Lunga PK, Wabo HK, Kuiate JR, Vilarem G, Giacinti G, Kikuchi H, Oshima Y: Antimicrobial and antioxidant properties of methanol extract, fractions and compounds from the stem bark of Entada abyssinica Stend ex A. Satabie. BMC Complement Altern Med 2011, 11:57.

34. Prakash D, Upadhyay $G$, Singh BN, Singh HB: Antioxidant and free radical-scavenging activities of seeds and agri-wastes of some varieties of soybean (Glycine max). Food Chem 2007, 104:783-790.

35. Kroyer GT: Red clover extract as antioxidant active and functional food ingredient. Innov Food Sci Emerg Technol 2004, 5:101-105.

36. Dajanta K, Apichartsrangkoon A, Chukeatirote E: Antioxidant properties and total phenolics of Thua Nao (a Thai fermented soybean) as affected by Bacillus-fermentation. J Microbial Biochem Technol 2011, 3:56-59.

37. Leong LP, Shui G: An investigation of antioxidant capacity of fruits in Singapore markets. Food Chem 2002, 7:69-75.

38. Re R, Pellegrini N, Proteggente A, Pannala A, Yang M, Rice-Evans C: Antioxidant activity applying an improved ABTS radical cation decolorization assay. Free Radic Biol Med 1999, 26:1231-1237.

39. Miguel G, Simões M, Figueiredo AC, Barroso JG, Pedro LG, Carvalho L: Composition and antioxidant activities of the essential oils of Thymus caespititius, Thymus camphoratus and Thymus mastichina. Food Chem 2004, 86:183-188.

40. Green LC, Wagner DA, Glogowski J, Skipper PL, Wishnok JS, Tannenbaum SR: Analysis of nitrate, nitrite, and [15N] nitrate in biological fluids. Anal Biochem 1982, 126:131-138.

41. Benzie IFF, Strain JJ: The ferric reducing ability of plasma (FRAP) as a measure of "antioxidant power": the FRAP assay. Anal Biochem 1996, 239:70-76.

42. Gao X, Ohlander M, Jeppsson N, Björk L, Trajkovski V: Changes in antioxidant effects and their relationship to phytonutrients in fruits of sea buckthorn (Hippophae rhamnoides) during maturation. J Agric Food Chem 2000, 48:1485-1490.

43. Ordon Ez AAL, Gomez JD, Vattuone MA, Isla Ml: Antioxidant activities of Sechium edule (Jacq.) swart extracts. Food Chem 2006, 97:452-458.

44. Kumaran A, Karunakaran RJ: In vitro antioxidant activities of methanol extracts of Phyllanthus species from India. LWT 2007, 40:344-352.

45. Price ML, Van Scoyoc S, Butler LG: A critical evaluation of the vanillin reaction as an essay for tannin in sorghum grain. J Agric Food Chem 1978, 25:1214-1218

46. Lichtenthaler $\mathrm{H}$, Wellburn $\mathrm{A}$ : Determination of total carotenoids and chlorophylls A and B of leaf in different solvents. Biochem Soc Trans 1983, 11:591-592.

47. Chen L, Vigneault C, Raghavan GSV, Kubow S: Importance of the phytochemical content of fruits and vegetables to human health. Stewart Posthar Rev 2007, 3:2

48. Ou B, Huang D, Hampsch-Woodill M, Flanagan JA, Deemer EK: Analysis of antioxidant activities of common vegetables employing oxygen radical absorbance capacity (ORAC) and ferric reducing antioxidant power (FRAP) assays: a comparative study. J Agric Food Chem 2002 50:3122-3128
49. Jeong WY, Jin JS, Cho YA, Lee JH, Park S, Jeong SW, Kim YH, Lim CS, Abd El-Aty AM, Kim GS, Lee SJ, Shim JH, Shin SC: Determination of polyphenols in three Capsicum annuum L. (Bell pepper) varieties using high-performance liquid chromatography-tandem mass spectrometry: their contribution to overall antioxidant and anticancer activity. J Sep Sci 2011, 34:2967-2974

50. Halliwell B, Gutteridge JMC: Free Radicals in Biological and Medicine. Oxford UK: Oxford University Press; 1999.

51. Guha G, Rajkumar V, Kumar RA, Mathew L: Therapeutic potential of polar and non-polar extracts of Cyanthillium cinereum in vitro. Evid Based Complement Alternat Med 2011, 2011:784826.

52. Lala PK, Chakraborty C: Role of nitric oxide in carcinogenesis and tumour progression. Lancet Oncol 2001, 2:149-156.

53. Oyedemi SO, Afolayan AJ: Antibacterial and antioxidant activities of hydroalcoholic stem bark extract of Schotia latifolia Jacq. Asian Pac J Trop Med 2011, 4:952-958.

54. Cakir A, Mavi A, Yildirim A, Duru ME, Harmandar M, Kazaz C: Isolation and characterization of antioxidant phenolic compounds from the aerial parts of Hypericum hyssopifolium L. by activity-guided fractionation. J Ethnopharmacol 2003, 87:73-83.

55. Aneta W, Jan O, Renata C: Antioxidant activity and phenolic compounds in 32 selected herbs. Food Chem 2007, 105:940-949.

56. Hong $Y$, Lin S, Jiang $Y$, Ashraf M: Variation in contents of total phenolics and flavonoids and antioxidant activities in the leaves of 11 Eriobotrya species. Plant Foods Hum Nutr 2008, 63:200-204.

57. Dr. Duke's Phytochemical and Ethnobotanical Databases. http://www.ars-grin. gov/duke/ Accessed 2012 Aug 10

doi:10.1186/1472-6882-13-259

Cite this article as: Dhar et al:: Chemical composition and antioxidant capacities of phytococktail extracts from trans-Himalayan cold desert. BMC Complementary and Alternative Medicine 2013 13:259.

\section{Submit your next manuscript to BioMed Central and take full advantage of:}

- Convenient online submission

- Thorough peer review

- No space constraints or color figure charges

- Immediate publication on acceptance

- Inclusion in PubMed, CAS, Scopus and Google Scholar

- Research which is freely available for redistribution 